This is the author's final, peer-reviewed manuscript as accepted for publication. The publisher-formatted version may be available through the publisher's web site or your institution's library.

\title{
Altering physical properties of pharmaceutical co-crystals in a systematic manner
}

Christer B. Aakeröy, Safiyyah Forbes, and John Desper

\section{How to cite this manuscript}

If you make reference to this version of the manuscript, use the following information:

Aakeröy, C. B., Forbes, S., \& Desper, J. (2014). Altering physical properties of pharmaceutical co-crystals in a systematic manner. Retrieved from http://krex.ksu.edu

\section{Published Version Information}

Citation: Aakeröy, C. B., Forbes, S., \& Desper, J. (2014). Altering physical properties of pharmaceutical co-crystals in a systematic manner. CrystEngComm, 16(26), 58705877.

Copyright: This journal is (c) The Royal Society of Chemistry 2014

Digital Object Identifier (DOI): doi:10.1039/c4ce00206g

Publisher's Link: http://pubs.rsc.org/en/content/articlehtml/2014/ce/c4ce00206g

This item was retrieved from the K-State Research Exchange (K-REx), the institutional repository of Kansas State University. K-REx is available at http://krex.ksu.edu 


\section{ARTICLE}

Cite this: DOI: $10.1039 / x 0 x x 00000 x$

\section{Altering physical properties of pharmaceutical co- crystals in a systematic manner}

Received 00th January 2012 ,

Accepted 00th January 2012

DOI: $10.1039 / \mathrm{x} 0 \mathrm{xx} 00000 \mathrm{x}$

www.rsc.org/

\author{
Christer B. Aakeröy, ${ }^{*}$ Safiyyah Forbes, and John Desper
}

\begin{abstract}
Systematic structure-property studies on a series of co-crystals of potential cancer drugs with aliphatic dicarboxylic acids were undertaken. This study reveals that systematic changes to the molecular nature of the co-crystallizing agent combined with control over the way individual building blocks are organized within the crystalline lattice makes it possible to establish predictable links between molecular structure and macroscopic physical properties, such as melting behaviour and aqueous solubility. However, it is not possible to find any notable correlation between physical properties-chemical compositions in the absence of structural consistency.
\end{abstract}

\section{Introduction}

Active pharmaceutical ingredients (APIs) can exist in a variety of distinct crystalline forms, where each form may display unique properties such as morphology, hygroscopicity, thermal stability, and solubility, all of which can be critical during formulation and for delivery and efficacy. ${ }^{1}$ Crystal engineering principles ${ }^{2}$ have been applied as a way of tailoring the physicochemical properties (i.e. melting point, solubility, dissolution rate and bioavailability) of APIs. ${ }^{3,5,6}$ In an earlier systematic study, we have reported that the melting behavior and solubility of $N, N^{\prime}$-bis(4-pyridinecarboxamide)1,6-hexane can be altered in a controllable manner without making or breaking covalent bonds. ${ }^{7}$

Altering the interactions between molecules can obviously have direct impact on the properties of the solid form of that particular compound, ${ }^{8}$ and co-crystals of pharmaceuticals can therefore achieve greater stability (shelf-life), bioavailability, solubility and enhanced potency compared to the APIs by themselves. ${ }^{9}$ However, it is still difficult to predict how the physical properties will be different with respect to the corresponding properties of the pure homomeric solids. To facilitate the preparation of new crystalline forms where we may be able to 'dial-in' some bulk behavior of a new solid form of an API, it would be very helpful to have access to synthetic protocols based on intermolecular interactions that can identify precise molecular recognition events that are likely to take place between a given API and a suitable co-crystallizing agent. ${ }^{10}$ In addition, in order to be able to systematically vary properties, it is essential to have considerable control over the metrics of the resulting crystal structures.

Previous work with bis(pyridinecarboxamido)alkanes (Ia,b and II) Scheme I, shows that self-complementary amide...amide N-H... O hydrogen bonds dominate the solidstate structures of such molecules, even in the presence of a potentially competitive hydrogen-bond acceptor such as a pyridyl moiety. ${ }^{11}$ These compounds are of pharmaceutical interest because the methylene bis-acetamide derivatives present in these APIs have been shown to be effective inducers of apoptosis of several cell lines. ${ }^{12}$ Moreover, the addition of a pyridyl moiety to the bis-acetamides has produced compounds capable of inhibiting the proliferation of lung cancer cells. ${ }^{13}$

Unfortunately, these compounds display poor aqueous solubility, which ultimately limits their usefulness and potential. We therefore set out to combine several of these molecules with inherently more soluble co-crystallizing agents with a view to enhancing the overall solubility of the API without interfering with its molecular structure. As cocrystallizing agents we opted for dicarboxylic acids because such compounds, ranging from succinic to dodecanedioic acid, are generally regarded as safe by the FDA. ${ }^{14}$ We can also use the well-established $\mathrm{COOH}$...N(py), O-H...N based synthon for driving the co-crystal synthesis in each case, ${ }^{15}$ Scheme 1. The combination of diacids with bis-pyridine building blocks is expected to produce infinite 1-D chains, and the amide moiety (which prefers a self-complementary $\mathrm{N}-\mathrm{H}$...O hydrogen bond 
over an $\mathrm{N}-\mathrm{H}$...N(py) interaction) can provide a cross-link between neighbouring chains, thus creating a 2-D assembly.

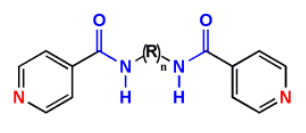

a: $\mathbf{R}=-\left(\mathrm{CH}_{2}\right)_{4} ; \mathrm{b}: \mathbf{R}=-\left(\mathrm{CH}_{2}\right)_{8}$

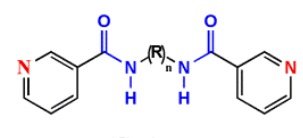

a: $\mathbf{R}=-\left(\mathrm{CH}_{2}\right)_{6}$
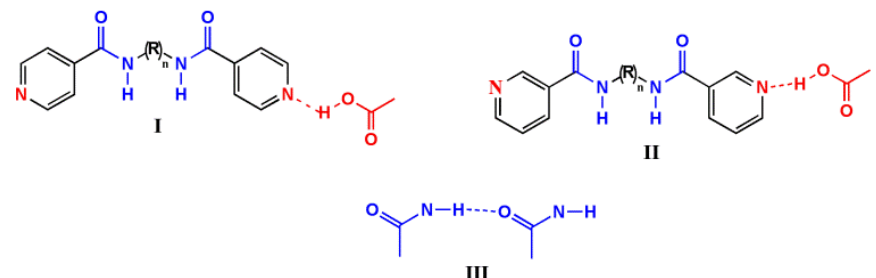

Scheme 1 Bis(pyridinecarboxamido) alkane molecules (Ia, Ib and IIa) with expected primary acid ${ }^{\cdots}$ pyridine synthons (I-II). The N-H hydrogen-bond donor with the amide $\mathrm{C}=\mathrm{O}$ (III).

The more structural control we can maintain upon moving through the series of dicarboxylic acids, the more likely it is that any physical property will change in a predictable manner. Modification of melting behavior and solubility plays a vital role in the development and formulation of APIs, and the rationale behind our approach to modulating properties through systematic co-crystal synthesis is readily illustrated by examining the melting points of even-chain aliphatic dicarboxylic acids as a function of carbon atom chain length, Figure 1. ${ }^{16}$ As long as the crystal structures remain more or less the same (the even-chain acids pack in very similar ways), there is a reasonable correlation between molecular structure (chain length in this case) and melting point, however as soon as we add an odd-chain acid into the series (which packs in a very different manner), the correlation is absent, Figure 1.

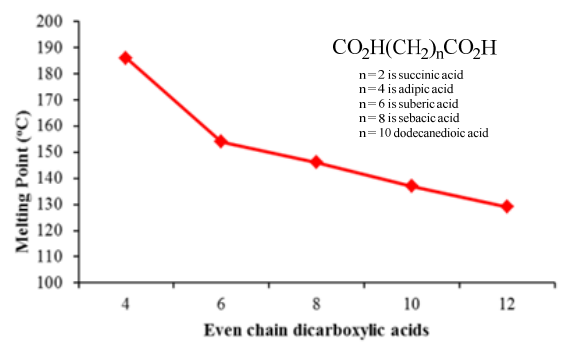

Figure 1 Melting points of aliphatic even chain (C4-C12) dicarboxylic acids plotted against the number of carbon atoms in each acid.

The take-home message from this is that in order to 'dial-in' physical properties, it is clear that (a) the nature of the individual building blocks matters and (b) the crystal structure matters. The goals of this study, therefore are (i) to establish structural consistency in a series of co-crystals driven by
$\mathrm{COOH} . . . \mathrm{N}(\mathrm{py})$ hydrogen bonds; (ii) to determine the sensitivity of the supramolecular synthesis to changes in molecular geometry of the API and/or co-crystallizing agent (the primary recognition sites will remain intact) and (iii) to establish if physical properties can be related in some ways to the molecular structure of the co-crystallizing agent.

\section{Experimental}

All chemicals were purchased from Aldrich or Acros Organics and used without further purification. Melting points were determined on a Gallenkamp melting point apparatus and are uncorrected. Compounds were prepared for infrared spectroscopic (IR) analysis as a mixture in $\mathrm{KBr}$ and $\mathrm{ZnSe}$ ATR crystal.

\section{Synthetic procedures}

Compounds Ia, $N, N^{\prime}$-bis(4-pyridinecarboxamide)-1,4-butane; Ib, $N, N^{\prime}$-bis(4-pyridinecarboxamide)-1,8-octane; IIa, $N, N^{\prime}$ bis(3-pyridinecarboxamide)-1,6-hexane; were synthesized and characterized according to previously reported methods. ${ }^{17}$ Each compound was subsequently co-crystallized with five different aliphatic diacids, Fig 2 (inset). Fifteen co-crystals were obtained, eleven of which produced crystal of sufficient quality to allow for single-crystal structure determination.

\section{Synthesis of $N, N^{\prime}$-bis(4-pyridinecarboxamide)-1,4-butane}

adipic acid (1:1), 1. $N, N^{\prime}$-bis(4-pyridinecarboxamide)-1,4butane Ia $(0.015 \mathrm{~g}, 0.053 \mathrm{mmol})$ was dissolved in $4 \mathrm{~mL}$ of ethanol-nitromethane (1:1) to which adipic acid $(0.007 \mathrm{~g}, 0.053$ $\mathrm{mmol})$ in $4 \mathrm{~mL}$ of ethanol-nitromethane (1:1) was added and allowed to evaporate at room temperature. Gold prisms were obtained after five days. Mp 201-203 ${ }^{\circ} \mathrm{C}$; (ZnSe ATR crystal) $v$ $2537 \mathrm{~cm}^{-1}, 1871 \mathrm{~cm}^{-1}$ (O-H...N, br), $3382 \mathrm{~cm}^{-1}$ (N-H amide), $1699 \mathrm{~cm}^{-1}(\mathrm{C}=\mathrm{O}$, acid, $\mathrm{s}), 1622 \mathrm{~cm}^{-1}(\mathrm{C}=\mathrm{O}$, amide, $\mathrm{s})$.

\section{Synthesis of $N, N^{\prime}$-bis(4-pyridinecarboxamide)-1,4-butane} suberic acid (1:1), 2. $N, N^{\prime}$-bis(4-pyridinecarboxamide)-1,4butane Ia $(0.015 \mathrm{~g}, 0.053 \mathrm{mmol})$ was dissolved in $4 \mathrm{~mL}$ of ethanol-nitromethane $(1: 1)$ to which a solution of suberic acid $(0.009 \mathrm{~g}, 0.053 \mathrm{mmol})$ in $4 \mathrm{~mL}$ of ethanol-nitromethane $(1: 1)$ was added and allowed to stand at room temperature to undergo slow evaporation. Colorless plates were obtained after ten days. Mp 196-198 ${ }^{\circ} \mathrm{C}$; (ZnSe ATR crystal) v $2500 \mathrm{~cm}^{-1}, 1875 \mathrm{~cm}^{-1}(\mathrm{O}-$ H...N, br), $3313 \mathrm{~cm}^{-1}$ (N-H amide), $1703 \mathrm{~cm}^{-1}$ (C=O, acid, s), $1629 \mathrm{~cm}^{-1}(\mathrm{C}=\mathrm{O}$, amide, $\mathrm{s})$.

Synthesis of $N, N^{\prime}$-bis(4-pyridinecarboxamide)-1,8-octane succinic acid (1:1), 3. A solution of $N, N$ '-bis(4pyridinecarboxamide)-1,8-octane $\mathbf{I b}(0.02 \mathrm{~g}, 0.056 \mathrm{mmol})$ in 5 $\mathrm{mL}$ ethanol was mixed with a solution of succinic acid $(0.007 \mathrm{~g}$, $0.056 \mathrm{mmol}$ ) in $5 \mathrm{~mL}$ of ethanol and was allowed to stand to slowly evaporate. Colorless plates were obtained after ten days. Mp: $185-187{ }^{\circ} \mathrm{C}$; (KBr pellet) v $2495 \mathrm{~cm}^{-1}, 1920 \mathrm{~cm}^{-1}$ (O-H...N, br), $3309 \mathrm{~cm}^{-1}$ (NH amide), $1704 \mathrm{~cm}^{-1}$ (C=O acid, s), $1630 \mathrm{~cm}^{-1}$ $(\mathrm{C}=\mathrm{O}$ amide, $\mathrm{s})$. 
Synthesis of $N, N^{\prime}$-bis(4-pyridinecarboxamide)-1,8-octane adipic acid (1:1), 4. A solution of $N, N^{\prime}$-bis(4pyridinecarboxamide)-1,8-octane $\mathbf{I b}(0.02 \mathrm{~g}, 0.056 \mathrm{mmol})$ in 5 $\mathrm{mL}$ ethanol was mixed with a solution of adipic acid $(0.008 \mathrm{~g}$, $0.056 \mathrm{mmol}$ ) in $5 \mathrm{~mL}$ of ethanol and was allowed to stand for slow evaporation. Colorless plates were obtained after fifteen days. Mp 160-162 ${ }^{\circ} \mathrm{C}$; KBr pellet) v $2500 \mathrm{~cm}^{-1}, 1922 \mathrm{~cm}^{-1}$ (O$\left.\mathrm{H}^{\cdots} \mathrm{N}, \mathrm{br}\right), 3320 \mathrm{~cm}^{-1}$ (NH amide), $1710 \mathrm{~cm}^{-1}$ ( $\mathrm{C}=\mathrm{O}$ acid, $\left.\mathrm{s}\right), 1638$ $\mathrm{cm}^{-1}(\mathrm{C}=\mathrm{O}$ amide, $\mathrm{s})$.

Synthesis of $N, N^{\prime}$-bis(4-pyridinecarboxamide)-1,8-octane suberic acid (1:1), 5. $N, N^{\prime}$-bis(4-pyridinecarboxamide)-1,8octane Ib $(0.02 \mathrm{~g}, 0.056 \mathrm{mmol})$ was dissolved in $5 \mathrm{~mL}$ of ethanol. To this solution was added suberic acid $(0.009,0.056$ $\mathrm{mmol}$ ) in $5 \mathrm{~mL}$ of ethanol. The resulting solution was allowed to stand at room temperature for slow evaporation. Colorless prisms were obtained after twenty days. $\mathrm{Mp} 163-165^{\circ} \mathrm{C}$; $(\mathrm{KBr}$ pellet) $\vee 2501 \mathrm{~cm}^{-1}, 1892 \mathrm{~cm}^{-1}\left(\mathrm{O}-\mathrm{H}^{\cdots} \mathrm{N}\right.$, br), $3317 \mathrm{~cm}^{-1}(\mathrm{NH}$ amide), $1706 \mathrm{~cm}^{-1}(\mathrm{C}=\mathrm{O}$ acid, $\mathrm{s}), 1635 \mathrm{~cm}^{-1} \quad(\mathrm{C}=\mathrm{O}$ amide, $\mathrm{s})$.

Synthesis of $N, N^{\prime}$-bis(4-pyridinecarboxamide)-1,8-octane sebacic acid (1:1), 6. $N, N^{\prime}$-bis(4-pyridinecarboxamide)-1,8octane Ib $(0.015 \mathrm{~g}, 0.0423 \mathrm{mmol})$ was dissolved in $4 \mathrm{~mL}$ of ethanol-nitromethane (1:1) to which a solution of sebacic acid $(0.009 \mathrm{~g}, 0.0423 \mathrm{mmol})$ in $4 \mathrm{~mL}$ of ethanol-nitromethane $(1: 1)$ was added and allowed to stand at room temperature for slow evaporation. Colorless plates were obtained after two weeks. Mp 162-163 ${ }^{\circ} \mathrm{C}$; (ZnSe ATR crystal) v $2520 \mathrm{~cm}^{-1}, 1871 \mathrm{~cm}^{-1}(\mathrm{O}-$ H...N, br), $3322 \mathrm{~cm}^{-1}$ (N-H amide), $1699 \mathrm{~cm}^{-1}$ (C=O, acid, s), $1631 \mathrm{~cm}^{-1}(\mathrm{C}=\mathrm{O}$, amide, $\mathrm{s})$.

Synthesis of $N, N^{\prime}$-bis(3-pyridinecarboxamide)-1,6-hexane succinic acid (1:1), 7. A solution of $N, N^{\prime}$-bis(3pyridinecarboxamide)-1,6-hexane II (0.02 g, $0.061 \mathrm{mmol})$ in $8 \mathrm{~mL}$ acetonitrile-ethyl acetate $(1: 1)$ was mixed a solution of succinic acid $(0.007 \mathrm{~g}, 0.061 \mathrm{mmol})$ in $2 \mathrm{~mL}$ of acetonitrileethyl acetate $(1: 1)$ and was allowed to stand at room temperature for slow evaporation. Colorless prisms were obtained after ten days. Mp $147-148{ }^{\circ} \mathrm{C}$; IR ( $\mathrm{KBr}$ pellet) $v 2481$ $\mathrm{cm}^{-1}, 1924 \mathrm{~cm}^{-1}\left(\mathrm{O}-\mathrm{H}^{\cdots} \mathrm{N}\right.$, br), $3309 \mathrm{~cm}^{-1}$ (N-H amide), 1690 $\mathrm{cm}^{-1}(\mathrm{C}=\mathrm{O}$, acid, $\mathrm{s}), 1637 \mathrm{~cm}^{-1}(\mathrm{C}=\mathrm{O}$, amide, $\mathrm{s})$.

Synthesis of $N, N^{\prime}$-bis(3-pyridinecarboxamide)-1,6-hexane adipic acid (1:1), 8. $N, N^{\prime}$-bis(3-pyridinecarboxamide)-1,6hexane II $(0.015 \mathrm{~g}, 0.046 \mathrm{mmol})$ was dissolved in $2 \mathrm{~mL}$ of ethanol-nitromethane (1:1) and adipic acid (0.007 $\mathrm{g}, 0.046$ $\mathrm{mmol})$ in $2 \mathrm{~mL}$ ethanol-nitromethane (1:1). The resulting solution was gently heated and left at room temperature for slow evaporation. After twenty days, colorless needles were obtained. Mp: $166-168{ }^{\circ} \mathrm{C}$; (ZnSe ATR crystal) v $2516 \mathrm{~cm}^{-1}$, $1895 \mathrm{~cm}^{-1}$ (O-H...N, br), $3309 \mathrm{~cm}^{-1}$ (N-H, amide), $1695 \mathrm{~cm}^{-1}$ ( $\mathrm{C}=\mathrm{O}$ acid, $\mathrm{s}), 1629 \mathrm{~cm}^{-1}(\mathrm{C}=\mathrm{O}$ amide, $\mathrm{s})$.

Synthesis of $N, N^{\prime}$-bis(3-pyridinecarboxamide)-1,6-hexane suberic acid (1:1), 9. $N, N^{\prime}$-bis(3-pyridinecarboxamide)-1,6hexane II $(0.015 \mathrm{~g}, 0.046 \mathrm{mmol})$ was dissolved in $10 \mathrm{~mL}$ nitromethane-ethylacetate (1:1) and mixed with a solution of suberic acid $(0.008 \mathrm{~g}, 0.046 \mathrm{mmol})$ in $5 \mathrm{~mL}$ of nitromethaneethyl acetate (1:1). The resulting solution was heated and allowed to stand at ambient temperature for slow evaporation. Colorless plates were obtained after four days. Mp 182-184 ${ }^{\circ} \mathrm{C}$; (ZnSe ATR crystal) v $2496 \mathrm{~cm}^{-1}, 1896 \mathrm{~cm}^{-1}\left(\mathrm{O}-\mathrm{H}^{\cdots \cdots} \mathrm{N}\right.$, br), 3329 $\mathrm{cm}^{-1}(\mathrm{NH}$ amide $), 1701 \mathrm{~cm}^{-1}(\mathrm{C}=\mathrm{O}$ acid, $\mathrm{s}), 1627 \mathrm{~cm}^{-1}(\mathrm{C}=\mathrm{O}$, amide, $\mathrm{s}$ ).

Synthesis of $N, N^{\prime}$-bis(3-pyridinecarboxamide)-1,6-hexane sebacic acid (1:1), 10. $N, N^{\prime}$-bis(3-pyridinecarboxamide)-1,6hexane II $(0.05 \mathrm{~g}, 0.14 \mathrm{mmol})$ was dissolved in $10 \mathrm{~mL}$ nitromethane-ethyl acetate (1:1) and mixed with a solution of sebacic acid ( $0.028 \mathrm{~g}, 0.14 \mathrm{mmol})$ in $5 \mathrm{~mL}$ nitromethane- ethyl acetate $(1: 1)$. The resulting solution was heated and allowed to stand at ambient temperature for slow evaporation. Colorless rods were obtained after ten days. Mp $180-181{ }^{\circ} \mathrm{C}$; ( $\mathrm{KBr}$ pellet) $v 2508 \mathrm{~cm}^{-1}, 1905 \mathrm{~cm}^{-1}\left(\mathrm{O}-\mathrm{H}^{\cdots \cdots} \mathrm{N}\right.$, br), $3305 \mathrm{~cm}^{-1}$ (NH amide), $1700 \mathrm{~cm}^{-1}(\mathrm{C}=\mathrm{O}$ acid, $\mathrm{s}), 1637 \mathrm{~cm}^{-1}(\mathrm{C}=\mathrm{O}$, amide, $\mathrm{s})$.

\section{Synthesis of $N, N^{\prime}$-bis(3-pyridinecarboxamide)-1,6-hexane} dodecanedioic acid (1:1), 11. $N, N^{\prime}$-bis(3pyridinecarboxamide)-1,6-hexane II (0.015 g, $0.046 \mathrm{mmol})$ was dissolved in $10 \mathrm{~mL}$ nitromethane-ethylacetate $(1: 1)$ and mixed with a solution of dodecanedioic acid $(0.011 \mathrm{~g}, 0.046 \mathrm{mmol})$ in $5 \mathrm{~mL}$ of nitromethane- ethyl acetate (1:1). The resulting solution was heated and allowed to stand at ambient temperature for slow evaporation. Colorless needles were obtained after five days. Mp 160-162 ${ }^{\circ} \mathrm{C}$; (ZnSe ATR crystal) v $2500 \mathrm{~cm}^{-1}, 1901 \mathrm{~cm}^{-1}\left(\mathrm{O}-\mathrm{H}^{\cdots \cdots} \mathrm{N}\right.$, br), $3302 \mathrm{~cm}^{-1}$ (NH amide), $1708 \mathrm{~cm}^{-1}$ ( $\mathrm{C}=\mathrm{O}$ acid, $\left.\mathrm{s}\right), 1625 \mathrm{~cm}^{-1}(\mathrm{C}=\mathrm{O}$, amide, $\mathrm{s})$.

Synthesis of $N, N^{\prime}$-bis(4-pyridinecarboxamide)-1,4-butane succinic acid (1:1), 12. $N, N$ '-bis(4-pyridinecarboxamide)-1,4butane Ia $(0.015 \mathrm{~g}, 0.053 \mathrm{mmol})$ was dissolved in $4 \mathrm{~mL}$ of ethanol-nitromethane (1:1) to which a solution of succinic acid $(0.006 \mathrm{~g}, 0.053 \mathrm{mmol})$ in $4 \mathrm{~mL}$ of ethanol-nitromethane $(1: 1)$ was added and allowed to stand at room temperature to undergo slow evaporation. Colorless needles were obtained after five days. Mp 227-229 ${ }^{\circ} \mathrm{C}$; (ZnSe ATR crystal) v $2504 \mathrm{~cm}^{-1}, 1973$ $\mathrm{cm}^{-1}$ (OH...N, br), $3382 \mathrm{~cm}^{-1}$ (N-H amide), $1699 \mathrm{~cm}^{-1}(\mathrm{C}=\mathrm{O}$, acid, $\mathrm{s}), 1625 \mathrm{~cm}^{-1}(\mathrm{C}=\mathrm{O}$, amide, $\mathrm{s})$.

Synthesis of $N, N^{\prime}$-bis(4-pyridinecarboxamide)-1,4-butane sebacic acid (1:1), 13.

$N, N$ '-bis(4-pyridinecarboxamide)-1,4-butane Ia (0.015 g, 0.053 mmol) was dissolved in $4 \mathrm{~mL}$ of ethanol-nitromethane (1:1) to which sebacic acid $(0.010 \mathrm{~g}, 0.053 \mathrm{mmol})$ in $4 \mathrm{~mL}$ of ethanolnitromethane (1:1) was added and allowed to stand at room temperature to slowly evaporate. Colorless needles were obtained after thirteen days. M.p.: $187-189^{\circ} \mathrm{C}$; (ZnSe ATR crystal) v $2496 \mathrm{~cm}^{-1}, 1913 \mathrm{~cm}^{-1}$ (O-H...N, br), $3188 \mathrm{~cm}^{-1}$ (N-H amide), $1697 \mathrm{~cm}^{-1}$ ( $\mathrm{C}=\mathrm{O}$ acid, $\left.\mathrm{s}\right), 1605 \mathrm{~cm}^{-1}$ ( $\mathrm{C}=\mathrm{O}$ amide, $\left.\mathrm{s}\right)$.

Synthesis of $N, N^{\prime}$-bis(4-pyridinecarboxamide)-1,4-butane dodecanedioic acid (1:1), 14. 
$N, N$ '-bis(4-pyridinecarboxamide)-1,4-butane Ia (0.015 g, 0.053 mmol) was dissolved in $4 \mathrm{~mL}$ of ethanol-nitromethane (1:1) to which dodecanedioic acid $(0.012 \mathrm{~g}, 0.053 \mathrm{mmol})$ in $4 \mathrm{~mL}$ of ethanol-nitromethane $(1: 1)$ was added and allowed to stand at room temperature to slowly evaporate. Colorless prisms were obtained after five days. M.p.: $182-184{ }^{\circ} \mathrm{C}$. (ZnSe ATR crystal) v $2500 \mathrm{~cm}^{-1}, 1875 \mathrm{~cm}^{-1}$ (O-H...N, br), $3305 \mathrm{~cm}^{-1}$ (N-H amide), $1710 \mathrm{~cm}^{-1}(\mathrm{C}=\mathrm{O}$ acid, $\mathrm{s}), 1626 \mathrm{~cm}^{-1}(\mathrm{C}=\mathrm{O}$ amide, $\mathrm{s})$.

Synthesis of $N, N^{\prime}$-bis(4-pyridinecarboxamide)-1,8-octane dodecanedioic acid (1:1), 15.

$N, N$ '-bis(4-pyridinecarboxamide)-1,8-octane Ib $\quad(0.015 \mathrm{~g}$, $0.0423 \mathrm{mmol}$ ) was dissolved in $4 \mathrm{~mL}$ of ethanol-nitromethane $(1: 1)$ to which dodecanedioic acid $(0.097 \mathrm{~g}, 0.0423 \mathrm{mmol})$ in 4 $\mathrm{mL}$ of ethanol-nitromethane $(1: 1)$ was added and allowed to stand at room temperature to evaporate. Colorless needles were obtained after ten days. M.p.: $154-156{ }^{\circ} \mathrm{C}$. (ZnSe ATR crystal) v $2514 \mathrm{~cm}^{-1}, 1900 \mathrm{~cm}^{-1}$ (O-H...N, br), $3326 \mathrm{~cm}^{-1}$ (N-H amide), $1707 \mathrm{~cm}^{-1}(\mathrm{C}=\mathrm{O}$ acid, $\mathrm{s}), 1632 \mathrm{~cm}^{-1}(\mathrm{C}=\mathrm{O}$ amide, $\mathrm{s})$.

\section{Solubility studies}

\section{Preparation of co-crystals for solubility studies}

Co-crystals of Ib and dicarboxylic acid (1:1 molar ratio) were prepared via a solvothermal method. ${ }^{18}$ Supersaturation of Ib and succinic acid was accomplished by cooling a solution of Ib $(0.5551 \mathrm{~g}, 1.566 \mathrm{mmol})$ and succinic acid $(0.1849,1.566$ $\mathrm{mmol}$ ) in $25.00 \mathrm{~mL}$ of ethanol from $40{ }^{\circ} \mathrm{C}$ to $25{ }^{\circ} \mathrm{C}$. The solid phase was harvested by vacuum filtration and dried at room temperature $\left(22-23{ }^{\circ} \mathrm{C}\right)$ on a Fisherbrand filter paper for $40 \mathrm{~min}$ to remove any adsorbed solvent. The solid obtained was confirmed to be a co-crystal by FT-IR spectroscopy; also the IR obtained matched the previous IR of crystals submitted for Xray analysis. Co-crystals were stored in a desiccator over anhydrous calcium sulfate. The remaining co-crystals were prepared and analyzed following the same procedure.

\section{Aqueous solubility of APIs and co-crystals}

The solubility of Ib and its respective co-crystals in water was determined from undersaturation by adding excess cocrystal solid phase in water. The suspensions were stirred with magnetic stirrers in a sealed $500 \mathrm{~mL}$ flask at constant temperature $\left(25 \pm 0.5{ }^{\circ} \mathrm{C}\right)$ maintained with a water bath. Samples were drawn at various time intervals over $72 \mathrm{hrs}$ and filtered. Samples were diluted with the same solvent in which the solubility analysis was performed. The solutions equilibrated within $48 \mathrm{hrs}$ and average sample concentration differed by $<3 \%$ at $24 \mathrm{hrs}$ and $48 \mathrm{hrs}$. Concentrations of samples were obtained measuring the absorbance of $\mathbf{I b}$ at $\lambda_{\max }$ $=234.8 \mathrm{~nm}$. All UV-Vis measurements were carried out on a Shimadzu UV-1650 PC.

Description of crystal structures of co-crystals 1-11. Co-crystallization reactions between Ia, Ib, II and even-chain aliphatic dicarboxylic acids were carried out, and IR spectroscopy was used to screen all of the resulting solids for co-crystal formation. We were also able to grow crystals suitable for single-crystal X-ray diffraction for eleven products. The crystal structures of $\mathbf{1}$ and $\mathbf{2}$ show that the API and the diacids are present in a 1:1 ratio, with hydrogen bonds between the pyridine nitrogen and the dicarboxylic acid in both structures, Table 1. The O-H...N interactions result in infinite 1-D chains, which are subsequently assembled into a 2-D sheet via the aid of amide...amide (N-H...O) interactions, Figure 2 and Figure 3, respectively.

The four crystal structures containing Ib are very similar in that each asymmetric unit consists of one molecule of $\mathbf{I b}$ and one molecule of the corresponding dicarboxylic acid. Again the acid...pyridine supramolecular synthon drives the co-crystal formation, Table 1, and the self-complementary amide... amide hydrogen bond produces a sheet-like architecture, Figures 4-5.

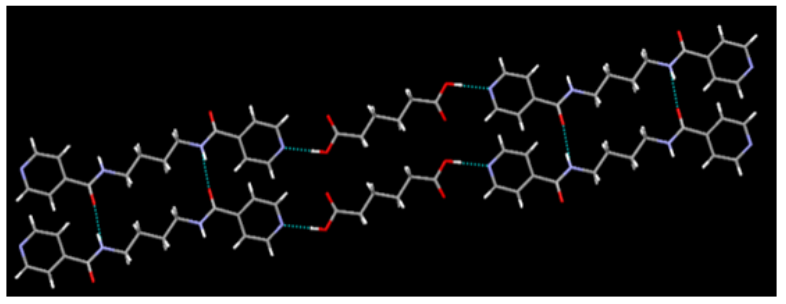

Figure 2 2-D sheet in the crystal structure of 1, held together by O$\mathrm{H} \ldots \mathrm{N}$ and $\mathrm{N}-\mathrm{H} . . . \mathrm{O}$ interactions.

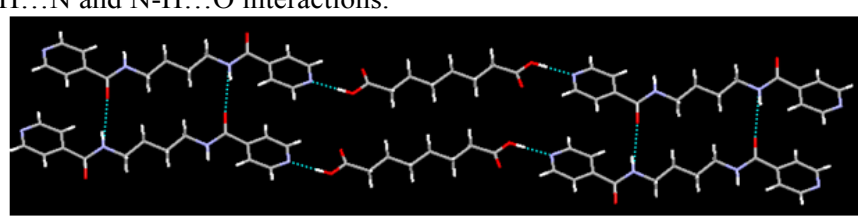

Figure 3 2-D sheet in the crystal structure of 2 held together by O$\mathrm{H}$... N and $\mathrm{N}-\mathrm{H} . . . \mathrm{O}$ interactions.

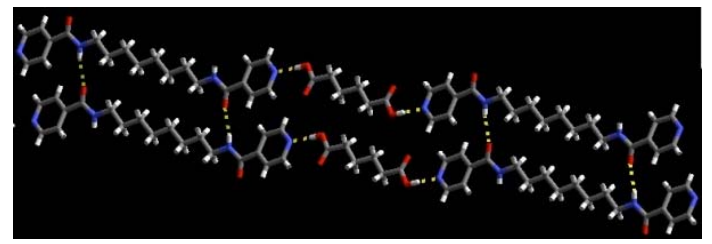

Figure 4 2-D sheet in the crystal structure of 4 , held together by O$\mathrm{H} . . \mathrm{N}$ and $\mathrm{N}-\mathrm{H}$...O interactions.

All five co-crystals of II display a 1:1 stoichiometry, and in each case the $\mathrm{COOH} \ldots \mathrm{N}($ py) interaction drives the assembly. However, there is a slight difference to the way in which the chains are arranged in these five structures. In 7, 8, 10 and 11, 1-D chains are cross-linked via amide....amide, N-H...O hydrogen bonds, resulting in 2-D corrugated sheets, Figs. 6-7, for two such examples.

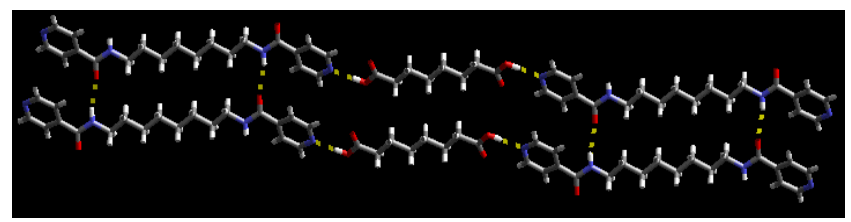

Figure 5 2-D sheet in the crystal structure of 5 , held together by $\mathrm{O}$ $\mathrm{H}$... $\mathrm{N}$ and $\mathrm{N}-\mathrm{H} . . . \mathrm{O}$ interactions 
However, although the crystal structure of $\mathbf{9}$ contains 1-D chains as well as amide... amide homosynthons, the overall layer is much more planar, Figure 8, and more similar to the architectures that were found in the structures of 1-6. 


\begin{tabular}{|c|c|c|c|c|c|}
\hline Compound & D-H...A & $\mathrm{d}(\mathrm{D}-\mathrm{H}) / \AA$ & $\mathrm{d}(\mathrm{H} . . . \mathrm{A}) / \AA$ & $\mathrm{d}(\mathrm{D} \ldots \mathrm{A}) / \AA$ & $<(\mathrm{DHA}) / \mathrm{deg}$ \\
\hline \multirow[t]{2}{*}{1} & $\mathrm{O}(31)-\mathrm{H}(31) \ldots \mathrm{N}(11)$ & $0.908(14)$ & $1.788(14)$ & $2.6940(9)$ & $175.0(13)$ \\
\hline & $\mathrm{N}(17)-\mathrm{H}(17) \ldots \mathrm{O}(17)^{* * *}$ & $0.864(13)$ & $2.139(13)$ & $2.9876(9)$ & $167.1(12)$ \\
\hline \multirow[t]{2}{*}{2} & $\mathrm{O}(31)-\mathrm{H}(31) \ldots \mathrm{N}(11)$ & $0.909(14)$ & $1.756(16)$ & $2.6942(11)$ & $178.7(14)$ \\
\hline & $\mathrm{N}(17)-\mathrm{H}(17) \ldots \mathrm{O}(17)^{* * *}$ & $0.880(14)$ & $2.130(14)$ & $2.9920(11)$ & $166.1(12)$ \\
\hline \multirow[t]{2}{*}{3} & $\mathrm{O}(31)-\mathrm{H}(31) \ldots \mathrm{N}(11)$ & $0.896(19)$ & $1.817(19)$ & $2.7128(15)$ & $178.3(18)$ \\
\hline & $\mathrm{N}(17)-\mathrm{H}(17) \ldots \mathrm{O}(17)^{* *}$ & $0.844(16)$ & $2.150(15)$ & $2.9834(14)$ & $169.5(15)$ \\
\hline \multirow[t]{2}{*}{4} & $\mathrm{O}(31)-\mathrm{H}(31) \ldots \mathrm{N}(11)$ & $0.925(15)$ & $1.782(15)$ & $2.7056(11)$ & $176.3(18)$ \\
\hline & $\mathrm{N}(17)-\mathrm{H}(17) \ldots \mathrm{O}(17)^{* *}$ & $0.848(14)$ & $2.170(14)$ & $3.0039(12)$ & $167.9(13)$ \\
\hline \multirow[t]{2}{*}{5} & $\mathrm{O}(31)-\mathrm{H}(31) \ldots \mathrm{N}(11)$ & $0.905(18)$ & $1.798(18)$ & $2.7026(14)$ & $177.21(17)$ \\
\hline & $\mathrm{N}(17)-\mathrm{H}(17) \ldots \mathrm{O}(17)^{*}$ & $0.853(17)$ & $2.173(17)$ & $3.00067(14)$ & $165.5(15)$ \\
\hline \multirow[t]{2}{*}{6} & $\mathrm{O}(31)-\mathrm{H}(31) \ldots \mathrm{N}(11)$ & $0.96(2)$ & $1.73(2)$ & $2.6912(17)$ & $178.6(18)$ \\
\hline & $\mathrm{N}(17)-\mathrm{H}(17) \ldots \mathrm{O}(17)^{*}$ & $0.899(19)$ & $2.125(19)$ & $2.9984(16)$ & $163.5(16)$ \\
\hline \multirow[t]{3}{*}{7} & $\mathrm{O}(31 \mathrm{~A})-\mathrm{H}(31 \mathrm{~A}) \ldots \mathrm{N}(11)$ & 0.84 & 1.81 & $2.6488(10)$ & 176.8 \\
\hline & $\mathrm{O}(31 \mathrm{~B})-\mathrm{H}(31 \mathrm{~B}) \ldots \mathrm{N}(11)$ & 0.84 & 2.06 & $2.894(7)$ & 173.6 \\
\hline & $\mathrm{N}(17)-\mathrm{H}(17) \ldots \mathrm{O}(17)^{* * *}$ & $0.852(12)$ & $2.089(12)$ & $2.9244(9)$ & $166.8(11)$ \\
\hline \multirow[t]{2}{*}{8} & $\mathrm{O}(31)-\mathrm{H}(31) \ldots \mathrm{N}(11)$ & $1.010(17)$ & $1.704(17)$ & $2.7137(15)$ & $177.2(15)$ \\
\hline & $\mathrm{N}(17)-\mathrm{H}(17) \ldots \mathrm{O}(17)^{*}$ & $0.835(17)$ & $2.110(18)$ & $2.9394(14)$ & $172.1(15)$ \\
\hline \multirow[t]{2}{*}{9} & $\mathrm{O}(31)-\mathrm{H}(31) \ldots \mathrm{N}(11)$ & $1.00(3)$ & $1.73(3)$ & $2.728(2)$ & $175(2)$ \\
\hline & $\mathrm{N}(17)-\mathrm{H}(17) \ldots \mathrm{O}(17)^{*}$ & $0.80(2)$ & $2.24(2)$ & $3.021(2)$ & $165.6(19)$ \\
\hline \multirow[t]{2}{*}{10} & $\mathrm{O}(31)-\mathrm{H}(31) \ldots \mathrm{N}(11)$ & $0.935(19)$ & $1.748(19)$ & $2.6802(13)$ & $175.0(15)$ \\
\hline & $\mathrm{N}(17)-\mathrm{H}(17) \ldots \mathrm{O}(17)^{*}$ & $0.913(16)$ & $1.997(16)$ & $2.8953(12)$ & $167.6(13)$ \\
\hline \multirow[t]{2}{*}{11} & $\mathrm{O}(31)-\mathrm{H}(31) \ldots \mathrm{N}(11)$ & $0.862(19)$ & $1.826(19)$ & $2.6839(15)$ & $173.7(17)$ \\
\hline & $\mathrm{N}(17)-\mathrm{H}(17) \ldots \mathrm{O}(17)^{* * *}$ & $0.851(18)$ & $2.060(18)$ & $2.8993(14)$ & $169.1(15)$ \\
\hline
\end{tabular}

${ }^{*} \mathrm{x}+1, \mathrm{y}, \mathrm{z} ;{ }^{* *} \mathrm{x}, \mathrm{y}-1, \mathrm{z} ;{ }^{* * *} \mathrm{x}-1, \mathrm{y}, \mathrm{z}$
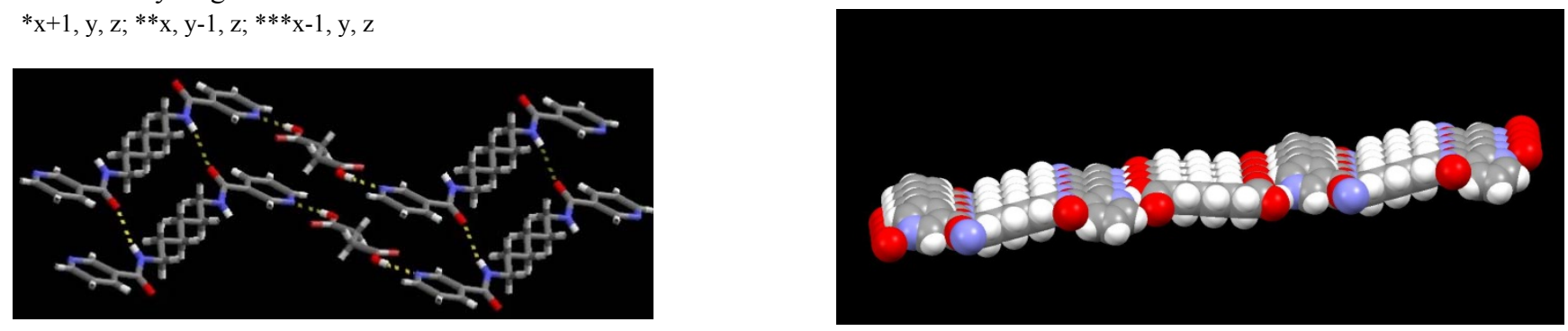

Figure 6 2-D zig-zag layer in 7 held together via O-H...N and NH...O hydrogen bonds.

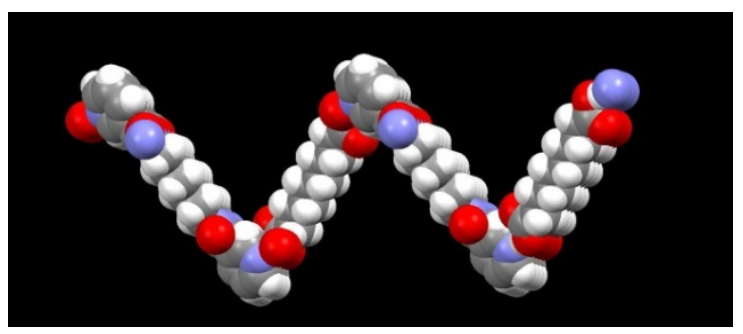

Figure $72-\mathrm{D}$ corrugated layer in the crystal structure of 10 formed through $\mathrm{O}-\mathrm{H} \ldots \mathrm{N}$ and $\mathrm{N}-\mathrm{H}$... O hydrogen bonds.

Figure 8. A flat layer in the crystal structure of 9. This motif is the only structural outlier in the five structures with II.

\section{Addressing structural consistency}

The intermolecular interactions observed in the series of cocrystals are remarkably consistent. In all eleven cases the pyridine nitrogen...acid heterosynthon was detected through both IR spectroscopy and single-crystal X-ray diffraction. Furthermore, the amide...amide homosynthon was also observed in all eleven co-crystals reported herein. In seven of the eleven structures, the outcome was a 2-D layered construction where the individual layers were flat (this was true for all structures from Ia and Ib, and one from II). The remaining crystal structures (all with II) contained highly corrugated 2-D assemblies, even though the synthons were 
identical to the ones found in the seven structures with flat layers.

\section{Fine-tuning the melting behavior of Ia-b}

It has previously been shown that co-crystallization can be used as a tool for improving the thermal stability ${ }^{19}$ as well as other physicochemical properties ${ }^{4,5,6,7}$ of several APIs. With this in mind, and having achieved considerable structural consistency (no outliers with either Ia or Ib) we subsequently examined whether the melting behavior of co-crystals formed with Ia, Ib could be correlated with any molecular feature of the five evennumbered dicarboxylic acids. Melting points were recorded for all co-crystals of $\mathbf{I a}$ and $\mathbf{I b}$, and plotted against the melting points of the corresponding pure acids, Figures 9-10. The data clearly show that the melting points of these five solids are directly related to the melting points of the pure acids.

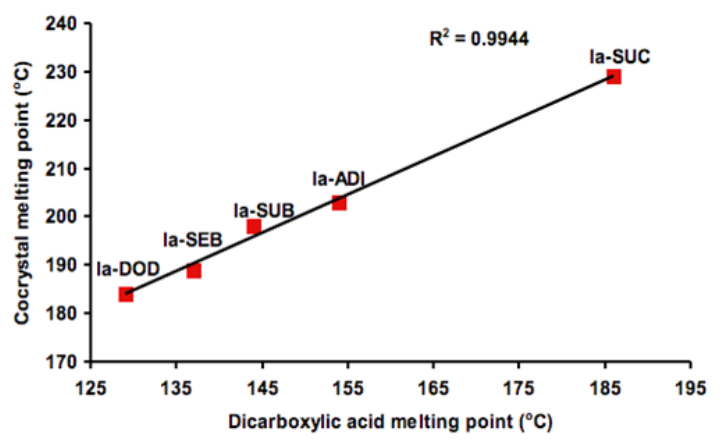

Figure 9 Melting points of co-crystals of Ia vs. melting points of corresponding diacids; where $\mathbf{S U C}=$ succinic; $\mathbf{A D I}=$ adipic; $\mathbf{S U B}=$ suberic; $\mathbf{S E B}=$ sebacic and $\mathbf{D O D}=$ dodecanedioic acid.

The co-crystal in each series displays a higher melting point than the corresponding pure diacid; this is presumably because of the additional strong hydrogen bonds that take place between acid and pyridine combined with efficient close packing of the planar layers. Thus, in Ia, the highest-melting co-crystal contains the dicarboxylic acid with the highest melting point, and the lowest-melting acid produces the lowest-melting cocrystal.

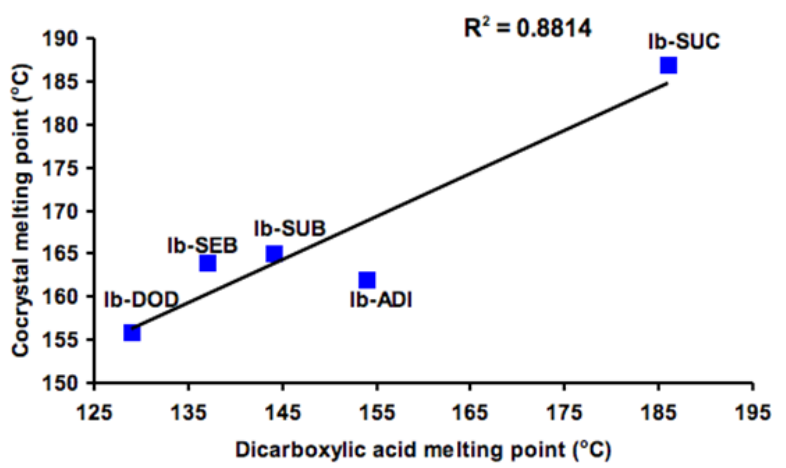

Figure 10 Melting points of co-crystals of Ib vs. melting points of the corresponding diacids.
These results demonstrate that it is possible to modulate the melting behavior of a given API in a highly predictable and controlled manner, over a significant range $\left(184-229{ }^{\circ} \mathrm{C}\right.$; the melting point of the API itself is $230-232{ }^{\circ} \mathrm{C}$ ). Likewise, Ib demonstrated similar trends with melting points of co-crystals ranging from $156-187^{\circ} \mathrm{C}$ (the melting point of the API itself is $165-166^{\circ} \mathrm{C}$ ).

Interestingly, there is also a connection between the density of the co-crystals and the density of the relevant acid, Fig. 11. The five co-crystals of II show a similar linear correlation with an $\mathrm{R}^{2}$-value of 0.93 .

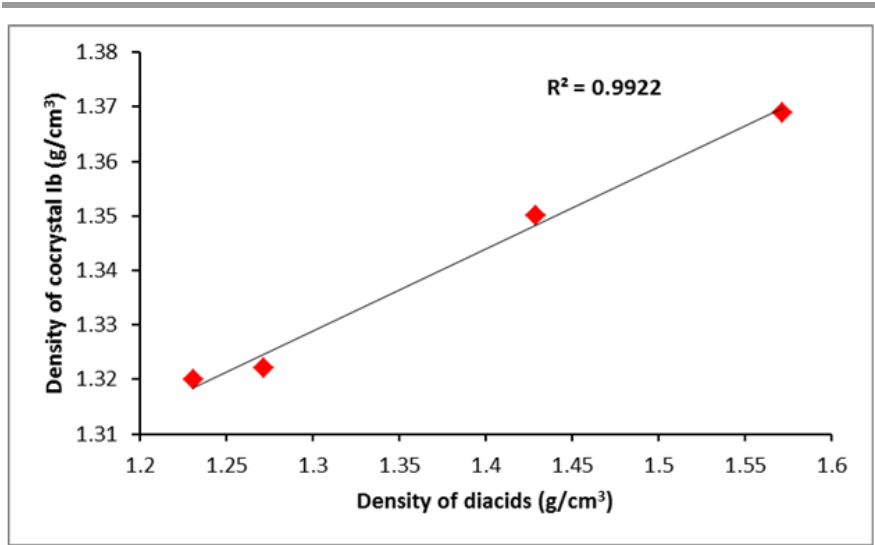

Figure 11 Crystal densities of co-crystals of Ib vs. the densities of the corresponding diacids.

This again is likely due to the fact that there is considerable structural consistency within the crystal structures of Ib and II, and we may even begin to think about each supramolecular chain as an individual molecular species, the chemical composition of which is altered in a step-wise manner by adding two $-\mathrm{CH}_{2}$ - groups from one molecule to the next.

Additionally, the melting point alteration in this series constitutes a readily explainable change in the physical properties of a pure component series as a consequence of cocrystal formation. The change in chain-length of the API (butane vs. octane) has no effect on predictability, the same synthons as well as the overall structures are present in both series Ia and Ib.

However, switching from a 4,4' isomer to a 3,3'-isomer (as from I to II) does have a detrimental effect establishing a correlation between molecular structure and physical properties. The relevant plot is shown in Figure 12, and it is clear that nothing can be inferred about bulk properties based upon molecular structure.

This is of course not unexpected since we have lost the structural consistency in this series, whereas co-crystals of $\mathbf{I a} / \mathbf{b}$ all contained the same general features.

\section{Altering aqueous solubility}

Although thermal properties are important, aqueous solubility is one of the key physicochemical parameters of a 
drug substance that needs to be assessed early on in the drug discovery process and optimized in the latter formulation stages. The results show that the aqueous solubility of $\mathbf{I b}$ can in fact be improved by a factor of 4.5 without altering the molecular structure of the API itself, Figure 13. Although the solubility of the co-crystals of Ib did not produce a linear correlation with the aliphatic even-chain dicarboxylic acids, as did the melting points, the trend in physicochemical properties of the co-crystals can certainly be rationalized in terms of the aqueous solubility of the dicarboxylic acids. The co-crystals of the less polar and more hydrophobic longer-chain diacids show a reduced aqueous solubility relative to that of the API itself.

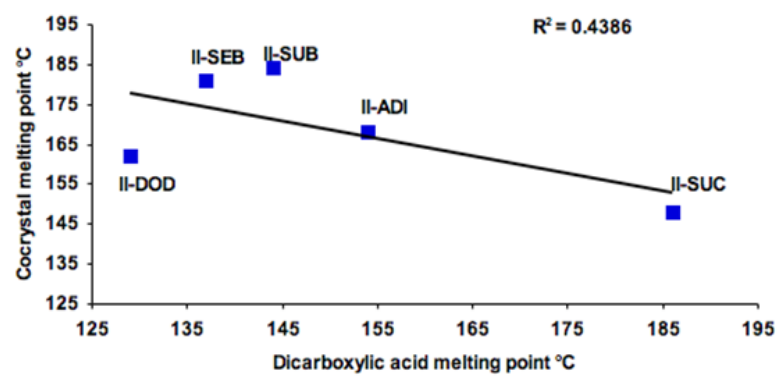

Figure 12 Melting points of co-crystals of II vs. melting point of the corresponding diacids.

Furthermore, when comparing this result to our previously reported study on the solubility of a similar compound with a shorter methylene chain length, ${ }^{7}$ it is interesting to note that the solubility of the API with a longer methylene chain length is significantly lower than those with a shorter chain length. Moreover, a significant increase in solubility is observed upon co-crystallization when the solubility of the API itself is very poor.

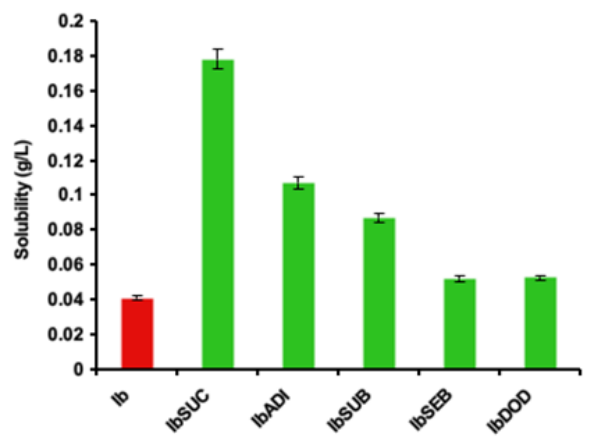

Figure 13 Aqueous solubility of $\mathbf{I b}$ and five co-crystals thereof.

\section{Conclusions}

We were able to show that Ia, Ib and II are capable of forming co-crystals with aliphatic even-chain dicarboxylic acids, where the driving force for co-crystal formation is the strong COOH....N(py) hydrogen bond. A high degree of structural consistency was found, which was reflected in a positive correlation between molecular characteristics and bulk physical properties. We were also able to show that the melting behaviour of Ia and Ib can be modulated in a predictable fashion without making or breaking covalent bonds.

However changing the geometry of the API changes both the packing motif and the melting behaviour as shown by the co-crystals of II. This provides us with additional information as to how changing carbon chain length and geometry will affect the structural and physical properties of a given compound. It is clear that structural consistency is a requirement for being able to connect molecular shape/property to predictable physical properties of the corresponding bulk solids in a series of related compounds.

Although it is obvious that not every co-crystal will deliver an improvement in physicochemical properties relative to that of the active ingredient, we have shown that systematic changes to the molecular nature of the co-crystallizing agent combined with control over the way that the individual building blocks are organized within the crystalline lattice makes it possible to establish predictable links between molecular structure and macroscopic physical properties. In this context, co-crystals may therefore offer unique opportunities for developing new solid forms in which a variety of desired physical properties can be tuned in a predictable manner.

\section{Acknowledgements}

We are grateful for financial support from the Johnson Cancer Research Center at Kansas State University.

\section{Notes and references}

${ }^{a}$ Author to whom correspondence should be addressed, Mailing address: Department of Chemistry, Kansas State University, 213 CBC Building, Manhattan, KS. Fax: 1.785.532.6666.

Tel: 1.785.532.6096. E-mail: aakeroy@ksu.edu.

Electronic Supplementary Information (ESI) available: [Crystallographic information (.cif). This material is available free of charge via the Interet]. See DOI: $10.1039 / \mathrm{b} 000000 \mathrm{x} /$
1 (a) C.B. Aakeröy, M.E Fasulo, J. Desper, Molecular Pharmaceutics 2007, 4, 317-322; (b) O. Almarsson, M.J. Zaworotko, Chem. Commun. 2004, 1889-1896; (c) P. Vishweshwar, J. McMahon, J.A Bis, M.J. Zaworotko, J. Pharmaceutical Sciences 2006, 95, 499-516.

2 (a) I. Goldberg, CrystEngComm. 2008, 10, 637-645; (b) C.B. Aakeröy, J. Desper, B. Levin, CrystEngComm. 2005, 7, 102-107; (c) R. Banerjee, B.K. Saha, G. Desiraju, CrystEngComm. 2006, 8, 680-685; (d) B.K. Saha, A. 
Nangia, M. Jaskólski, CrystEngComm. 2005, 7, 355-358; (e) C.M. Reddy, L.S. Reddy, S. Artipamula, A. Nangi, C.-K. Lam, T.C.W. Mak, CrystEngComm. 2005, 7, 44-52; (f) D. Braga, L. Brammer, N.R. Champness, CrystEngComm. 2005, 7, 1-19; (g) A. Nangia, CrystEngComm., 2002, 4, 93-101.

3 (a) A.V. Trask, S.W.D. Motherwall, W. Jones, International Journal of Pharmaceutics 2006, 320, 114-123; (b) N. Shan, J. Zaworotko, Drug Discovery Today 2008, 13, 440-446; (c) J.F. Remenar, S.L. Morissette, M.L. Peterson, B. Moulton, J.M. MacPhee, H.R. Guzmán, Ö. Almarsson, J. Am. Chem. Soc. 2003, 125, 8456-8457; (d) R.D. Bailey Walsh, M.W. Bradner, S. Fleischman, L.A. Morales, B. Moulton, N. Rodrìguez-Hornedo, M.J. Zaworotko, Chem. Commun. 2003, 186-187.

4 (a) N.J. Babu, A. Nangia, Cryst. Growth Des. 2011, 11, 2662-2679; (b) D.P. McNamara, S.L. Childs, J. Giordano, A. Iarriccio, J. Cassidy, M.S. Shet, R. Mannion, A. Park, Pharmacetuical Research 2006, 23, 1888-1897; (c) S.L. Childs, L.C. Chyall, J.T. Dunlap, V.N. Smolenskaya, B.C. Stahyl, G.P. Stahly, J. Am. Chem. Soc. 2004, 126, 13335-13342.

5 T. Zhang, Y.Yang, H. Wang, F. Sun, X. Zhao, J. Jia, J. Liu, W. Guo, X. Cui, J. Gu and G. Zhu, Cryst. Growth Des. 2013, 13, 5261- 5266; P. Sanphui, S. Tothadi, S. Ganguly, G.R. Desiraju, Mol. Pharmaceutics, 2013, 10, $4687-$ 4697; A. Shevchenko, I. Miroshnyk, L.-O. Pietilä, J. Haarala, J. Salmia, K. Sinervo, S. Mirza, B. van Veen, E. Kolehmainen, N. Nonappa, J. Yliruusi, Crystal Growth \& Design, 2013, 13 .4877-4884; R. Thakuria, A. Nangia, Crystal Growth \& Design, 2013, 13, 3672-3680; M. Baldrighi, G. Cavallo, M. R. Chierotti, R. Gobetto, P. Metrangolo, T. Pilati, G. Resnati, G. Terraneo, Mol. Pharmaceutics, 2013, 10, 1760-1772; A. Newman, Org. Process Res. Dev., 2013, 17, 457-471.

6 J. Wouters, F. Grepioni, D. Braga, R. M. Kaminski, S. Rome, L. Aerts, L. Quéré, CrystEngComm, 2013,15, 8898-8902; C. C. da Silva, M. de Lima Cirqueira, F. T. Martins, CrystEngComm, 2013,15, 6311-6317; A.B.M. Buanz, R. Telford, I. J. Scowen, S. Gaisford, CrystEngComm, 2013,15, 1031-1035; C.B. Aakeröy, S. Panikkattu, B. DeHaven, John Desper, CrystEngComm, 2013,15, 463-470; C.B. Aakeröy, S. Forbes, J. Desper, CrystEngComm, 2012,14, 2435-2443; S. Ghosh, C. M. Reddy, CrystEngComm, 2012,14, 2444-2453; D. Rossi, T. Gelbrich, V. Kahlenberg, U. J. Griesser, CrystEngComm, 2012,14, 2494-2506; M. R. Caira, S.A. Bourne, H. Samsodien, E. Engel, W. Liebenberg, N. Stieger, M. Aucamp,

CrystEngComm, 2012,14, 2541-2551; S. L. Bekö, M.U. Schmidt, A. D. Bond CrystEngComm, 2012,14, 1967-1971; V.R. Vangala, P.S. Chow, R.B. H. Tan CrystEngComm, 2011,13, 759-762.

7 C. Aakeröy, S. Forbes, J. Desper, J. Am. Chem. Soc. 2009, 31, 1704817049 .

8 (a) N. Schultheiss, A. Newman, Cryst. Growth Des. 2009, 9, 2950-2967; (b) S. Datta, D.J.W. Grant, Nat. Rev. Drug Discovery 2004, 3, $42-57$.

9 (a) D.J. Berry, C.C. Seaton, W. Clegg, R.E. Harrington, S.J. Coles, P.N. Horton, M.B. Hursthouse, R. Storey, W. Jones, T. Fris 'c ' ${ }^{2}$ 'c', N. Blagden, Cryst. Growth Des. 2008, 8, 1697-1712; (b) P. Vishweshwar, J.A. McMahon, M.L. Peterson, M.B. Hickey, T.R. Shattock, M.J. Zaworotko, Chem. Commun. 2005, 4601-4603; (c) R. Banerjee, P.M. Bhatt, N.V. Ravindra, G.R. Desiraju, Cryst. Growth Des., 2005, 5, 2299-2309.

10 (a) G.A. Broker, R.P.A. Bettens, E.R.T. Tiekink, CrystEngComm. 2008, 10, 879-887; (b) J.A. Bis, P. Vishweshwar, D. Weyna, M.J. Zaworotko, Mol. Pharmacol. 2007, 4, 401-416.

11 M. Sarkar, K. Biradha, Cryst. Growth Des. 2006, 6, 202-208.

12 M. Andreeff, R. Stone, J. Michaeli, C.W. Young, W.P. Tong, H. Sogologg, T. Ervin, D. Kufe, R.A. Rifkind, P.A. Marks, Blood, 1992, 80, 2604-2609.
13 E. Ao, R. Tanaka, K. Yamagami, A. Fujii, Jpn. Patent 03081222, 1991. 14 FDA Select Committee on GRAS Substances (SCOGS) Database Overview. http://www.cfsan.fda.gov/opascogs.html

15 (a) C.V.K. Sharma, M.J. Zaworotko, Chem. Commun. 1996, 2655; (b) C..B Aakeröy, I. Hussain, S. Forbes, J. Desper, CrystEngComm. 2006, 8, 110; (c) B.R. Bhogala, P. Vishweshwar, A. Nangia, Cryst. Growth Des. 2002, 2,325 .

16 (a) V.R. Thalladi, M. Nüsse, R. Boese, J. Am. Chem. Soc., 2000, 122, 9227-9236; (b) P. Vishwesher, A. Nangia, V.M. Lynch, Cryst. Growth and Des. 2003, 3, 783-790; (c) J.D. Morrison, J.M. Robertson, J. Chem. Soc. 1949, 980; (d) H.J. Verweel, C.H. MacGillavry, Nature 1938, 142, 161. 17 S. Mutha, J. Yip, J. Vittal, J. Chem. Soc., Dalton Trans. 2002, 4561-4569. 18 S.J. Nehm, B. Rodríguez-Spong, N. Roderíguez-Hornedo, Cryst. Growth Des. 2006, 6, 592-600.

19 (a) N. Variankaval, R. Wenslow, J. Murry, R. Hartman, R. Helmy, E. Kwong, S.-D. Clas, C. Dalton, I. Santos, Cryst. Growth Des. 2006, 6, 690; (b) K. Seefeldt, J. Miller, F. Alvarez-Núñez, N. Rodríguez-Hornedo, J. Pharm. Sci. 2007, 96, 1147. 